\title{
UM GESTO DE LEITURA EM PÊCHEUX: SOBRE MÁQUINAS, INFORMÁTICA E ARQUIVO
}

\author{
ALEXANDRE DA SILVA ZANELLA ${ }^{1}$
}

Departamento de Letras

Instituto Universitário de Pesquisas do Rio de Janeiro

R. da Assembleia, 10 - sala 709 - CEP: 20011-901 - Rio de Janeiro - RJ - Brasil

aleszanella@gmail.com

Resumo. Perseguimos o caminho traçado por Pêcheux em sua elaboração teórica da Análise de Discurso no que concerne à informática, às máquinas e ao arquivo. Nosso objetivo se faz a partir de um gesto de leitura que retoma a produção teórica pecheutiana iniciada nos anos de 1960, a qual incidia fortemente em reflexões sobre a linguística, o materialismo histórico e a psicanálise, atentando para um funcionamento específico que tinha também seu lugar: o das máquinas. Queremos fazer um mapeamento na obra de Pêcheux sobre questões relacionadas às máquinas e ao seu funcionamento, a fim de demonstrar como a tecnologia e a informática, e os discursos sobre elas, apresentam-se à luz da Análise de Discurso em sua relação com a linguagem. Para tanto, debruçamo-nos principalmente sobre a obra de Pêcheux (1969, 1975, 1981, 1982, 1983, 1984) e também em Maldidier (1993, 2003) e em Ferreira (2015).

Palavras-chave: discurso; máquinas; informática; arquivo; linguagem.

\begin{abstract}
We follow Michel Pêcheux's theoretical elaboration of Discourse Analysis, in relation to informatics, to machines and to archive. Our objective is given by a reading gesture that resumes Pêcheux's theoretical production started in the 1960s, which strongly focused on reflections on linguistics, historical materialism and psychoanalysis, noting a specific operation that also had its place: that of the machines. Therefore, we aim at mapping about questions related to machines and their operation in Pêcheux's work in order to demonstrate how technology and informatics, and discourses about them, are presented in light of the Discourse Analysis in its relation to language. For that reason, we especially focus on Michel Pêcheux's work (1969, 1975, 1981, 1982, 1983, 1984) and on Maldidier (1993, 2003) and on Ferreira (2015).
\end{abstract}

Keywords: discourse; machines; informatics; archive; language.

\footnotetext{
${ }^{1}$ Doutor em Estudos de Linguagem pela Universidade Federal Fluminense; professor na Universidade Candido Mendes (Campus IUPERJ). http://lattes.cnpq.br/9207684618730302.
} 
C'est par la construction d'un dispositif informatisé que commence l'aventure du discours!

(Denise Maldidier, 1993)

\section{Introdução}

A formação de um campo de saber como o da Análise de Discurso de linha pecheutiana se deu num constante ir e vir de questões que concerniam o discurso como objeto. Nesse movimento iniciado nos anos de 1960, em que se incidia fortemente sobre reflexões teóricas sobre a linguística, o materialismo histórico e a psicanálise, um funcionamento específico tinha também seu lugar: o das máquinas.

Michel Pêcheux, ainda num momento inaugural de formulação do campo teórico do discurso, debruçou-se intensamente sobre o tema das máquinas e da informática. Mas, como pretendo dar a saber neste trabalho, não se tratou apenas de um interesse inicial. Ao longo das várias fases de formulações e reformulações da teoria do discurso, Pêcheux deu continuidade às reflexões sobre as máquinas, sobre a informática, sobre o tecnológico.

Desse modo, tenho como objetivo, neste artigo, mapear na obra de Pêcheux algumas questões que se destacam relacionadas às máquinas e seu funcionamento, no intuito de demonstrar como o informático e o tecnológico, e os discursos sobre eles, apresentam-se à luz da Análise de Discurso.

Trata-se de uma reflexão incitada a partir de um projeto de que fiz parte intitulado "Divulgação científica em Análise do Discurso: investigação e inovação com base em novas tecnologias", proposto pela professora-pesquisadora Dra. Bethania Mariani e contemplado pelo Edital Humanidades ${ }^{2}$. O projeto foi realizado pelo Laboratório Arquivos do Sujeito (LAS), da Universidade Federal Fluminense (UFF), cuja coordenação compete às professoras Dra. Bethania Mariani, Dra. Silmara Dela Silva e Dra. Vanise Medeiros. O grupo de pesquisadores incluía professores-pesquisadores e alunos de Iniciação Científica, mestrado, doutorado e pós-doutorado. O objetivo principal do projeto era convidar professores-pesquisadores e gravar vídeos de até 5 (cinco) minutos sobre conceitos da Análise de Discurso, a fim de compor um arquivo de vídeosverbetes que seriam carregados no canal de vídeo da Universidade Federal Fluminense, o UFFtube ${ }^{3}$, e assim constituir uma enciclopédia audiovisual de conceitos da Análise de Discurso ( $c f$. LUNKES, 2016). O trabalho que apresento aqui é um desenvolvimento do que será publicado no $e$-book produzido por alguns pesquisadores envolvidos no projeto. ${ }^{4}$

\footnotetext{
${ }^{2}$ Edital Faperj n. ${ }^{\circ}$ 14/2013-Humanidades, processo n ${ }^{\circ}$ E-26/111.085/2013, vigente de setembro de 2013 a setembro de 2015.

${ }^{3} \mathrm{O}$ canal de vídeos da Universidade Federal Fluminense tem funcionamento próximo ao do Youtube.

${ }^{4}$ Como encerramento do projeto contemplado pelo Edital Humanidades (Edital Faperj n. ${ }^{\text {o }}$ 14/2013Humanidades, processo n. ${ }^{\circ}$ E-26/111.085/2013, vigente de setembro de 2013 a setembro de 2015), propôsse a produção de um $e$-book cujos capítulos abordassem questões teóricas e metodológicas relacionadas ao projeto, bem como outras reflexões despertadas a partir das discussões teóricas e do processo de gravação dos vídeos-verbetes que vieram a compor a Enciclopédia audiovisual de conceitos da Análise do Discurso.
} 


\section{Primeiras anotações em Pêcheux}

Inicio meu percurso a partir de uma afirmação de Michel Pêcheux de 1983, sobre algo que o autor havia escrito antes, em 1969: "Um processo de produção discursiva é concebido como uma máquina autodeterminada e fechada sobre si mesma [...]" (PÊCHEUX, 1983, p. 307; negrito meu).

Trata-se de uma anotação de Pêcheux sobre o que viria posteriormente a ser chamada de primeira fase da teoria da Análise de Discurso, ou AD-1. Neste primeiro momento de reflexões sobre a teoria do discurso, Pêcheux (1983) considerava que, para o trabalho analítico discursivo, devia-se partir de um corpus fechado de sequências discursivas produzidas por sujeitos - os quais, por sua vez, seriam determinados por um "sujeito-estrutura" (idem, p. 307), isto é, completamente assujeitados - num espaço discursivo estabilizado, com condições de produção supostamente homogêneas. Como lemos em Pêcheux, sobre o "método de dedução frequencial":

Designamos assim o processo que consiste em recensear o número de ocorrências de um mesmo signo linguístico (palavra ou lexia, mais frequentemente) no interior de uma sequência de dimensão fixada, e em definir uma frequência que pode ser comparada com outras, o que fornece um teste de comparabilidade entre vários itens da mesma sequência, ou entre várias sequências paralelas para o mesmo item. A grande vantagem desse método foi desenvolver instrumentos científicos adequados ao tratamento da informação [...]. (PÊCHEUX, [1969] 2010, p. 62)

Nesse método proposto pelo autor, seria possível distribuir as variações empíricas encontradas no corpus até chegar a uma estrutura da máquina discursiva que supostamente os havia produzido, como se houvesse uma matriz que dominasse tal produção, numa operação maquínica. Por isso se tratava de uma análise automática. Para Maldidier (2003, p. 20), "A elaboração de uma análise automática, isto é, de um dispositivo técnico complexo informatizado, se inscreve em sua reflexão de então sobre as práticas e os instrumentos científicos" (itálico da autora).

Esses procedimentos analíticos, detalhados por Pêcheux no texto Análise automática do discurso (AAD-69), só eram possíveis porque, segundo o autor, as máquinas discursivas seriam unidades fechadas sobre si mesmo e com uma capacidade de autodeterminação. ${ }^{5}$ Tal tomada de posição por Pêcheux é feita numa empreitada em que, por meio de fórmulas complexas, seria possível chegar a uma matriz de sentido. Tratava-se de uma máquina de leitura, na qual importava o dispositivo informatizado que a permitisse (por recenseamento, frequência, sequenciação, comparação e tratamento da informação, como reunimos a partir da citação acima).

Os significantes máquina, maquinaria, automatização que aparecem no texto da Análise Automática do Discurso (doravante, AAD-69) deflagram uma paixão de Pêcheux

\footnotetext{
${ }^{5}$ Apenas mais tarde Pêcheux iria verificar as relações desiguais que marcam os processos discursivos.
} 
pelas máquinas, para nos referirmos a Ferreira (SEAD/2015) ${ }^{6}$. Conforme esta autora, Pêcheux era um homem de muitas paixões, e a paixão pelas máquinas foi uma das que mais o agarraram - ao lado das paixões pela língua e pela política -, ao mesmo tempo em que foi uma das que sempre o acompanharam:

Desde o início, como AAD-69, se faz presente o dispositivo informatizado que implica uma teoria não-subjetiva do discurso. Essa é a máquina discursiva que Pêcheux apresenta à comunidade de intelectuais franceses, com todo o espanto e desconcerto que a obra produziu nos seus leitores. (FERREIRA, SEAD/2015)

As "máquinas", no entanto, não vieram sozinhas na teoria pecheutiana. Ao lado delas estavam outras questões que interessavam igualmente a Pêcheux: a do sujeito, a do sentido, a da política e a do político. Tais articulações que o autor projetava conferiram à teoria do discurso um caráter revolucionário, porque subvertiam o que vinha sendo pensado nas ciências sociais e nas teorias da linguagem que até então excluíam a questão da história - e, por conseguinte, a questão do sentido - da e na língua. Excluía-se, enfim, a materialidade. O que Pêcheux faz, desde um primeiro momento da Análise de Discurso, é reinserir o caráter material do sentido na língua. Como diz Paul Henry, "Pêcheux sempre teve como ambição abrir uma fissura teórica e científica" ([1969] 2010, p. 12). Refere-se este autor, naquele momento (1969), exclusivamente ao campo das ciências sociais e da psicologia social, e sabemos que para Pêcheux essa ambição se perpetuou em todas as suas empreitadas teóricas e metodológicas até o fim de sua vida.

Já naquele momento, o da AAD-69, o autor apoiava-se sobre os pilares que guiariam a formação da teoria materialista do discurso, os quais promoviam uma verdadeira reviravolta:

o materialismo histórico tal como Louis Althusser o havia renovado a partir de sua releitura de Marx; a psicanálise, tal como a formulou Jacques Lacan, através de seu "retorno a Freud", bem como certos aspectos do grande movimento chamado, não sem ambiguidades, de estruturalismo. [...] O que interessava a Pêcheux no estruturalismo eram aspectos que supunham uma atitude não reducionista no que se refere à linguagem. (HENRY, [1969] 2010, p. 13)

Ora, esses elementos se mostravam tão presentes na formulação teórica proposta por Pêcheux que, segundo Ferreira (SEAD/2015), só lhe foi possível pensar o sistema da análise automática do discurso devido a eles. Entretanto, essa tríade que fundamentava o pensamento pecheutiano não foi apresentada com o texto da AAD-69:

Pêcheux decidiu separar a apresentação de seu sistema de análise automática do discurso da apresentação dos problemas teóricos, filosóficos e políticos que o levaram a conceber tal sistema e isso lhe trouxe, como nos adianta Paul Henry (1990, p. 36), consequências sérias.

\footnotetext{
${ }^{6}$ Faço referência à conferência de abertura feita por Maria Cristina Leandro Ferreira, no VII Seminário de Estudos em Análise do Discurso (SEAD), realizado em Recife entre os dias 13 e 16 de outubro de 2015.
} 
As consequências foram que o instrumento da análise automática do discurso acabou sendo usado de forma empírica, indo na contramão do que Pêcheux propunha. Porque, ainda conforme Ferreira,

$\mathrm{O}$ que ele pretendia era ler objetivamente os textos, utilizando o dispositivo informatizado, afastando-se, assim, de uma leitura impressionista, subjetivista, conteudista. Na conjuntura da época dos anos 60, a AD se lançava como intervenção política fazendo da leitura crítica ideológica um modo de combater os positivismos das ciências régias, até então, dominantes. (FERREIRA, SEAD/2015)

Não obstante o desvio,

o efeito político principal, em parte foi atingido; uma fissura acaba sendo aberta no campo "inimigo", uma "cunha" é interposta com a apropriação feita dos instrumentos pela teoria. A AAD acaba sendo mobilizada (efeito "Cavalo de Troia") por vários pesquisadores das ciências sociais, que acabam assim conseguindo formular inúmeras questões, o que talvez não ocorresse sem o dispositivo utilizado. E esse efeito desestabilizador já representava um grande ganho. Para Pêcheux o que realmente importava eram as questões suscitadas pelo programa, mais até do que as respostas do instrumento. (FERREIRA, SEAD/2015)

Se Pêcheux esteve, como vimos afirmando, sempre vinculado, sempre atento, sempre coerente às suas propostas - e é possível visualizarmos isso nas retificações que percorreram sua obra, por exemplo -, não consideramos que se possa falar, de fato, no que concerne à Análise de Discurso, em fases de-limitadas. É bem verdade que Pêcheux apresenta, em artigo intitulado "A análise de discurso: três épocas (1983)", uma categorização da teoria; mas olhando pelo lado do fio condutor que unifica os diferentes momentos teóricos pelos quais passou, veremos que ele esteve sempre preocupado com suas paixões, vale frisarmos, pela língua, pelas máquinas, pela política. Com isto queremos dizer que, embora haja uma classificação em fases, algumas separações não são possíveis na prática.

E foram de fato as questões suscitadas a partir do dispositivo da maquinaria discursiva - a propósito, Maldidier (2003, p. 19, itálico da autora) nos diz que é no momento inaugural da AAD-69 que "se ligam - pela primeira vez - todos os fios constitutivos de um objeto radicalmente novo: o discurso" - que permitiram a Pêcheux, mais tarde, construir um campo teórico fortalecido, incidindo:

[...] na articulação de três regiões do conhecimento científico:

1. o materialismo histórico, como teoria das formações sociais e de suas transformações, compreendida aí a teoria das ideologias;

2. a linguística, como teoria dos mecanismos sintáticos e dos processos de enunciação ao mesmo tempo;

3. a teoria do discurso, como teoria da determinação histórica dos processos semânticos. 
Convém explicitar ainda que essas três regiões são, de certo modo, atravessadas e articuladas por uma teoria da subjetividade (de natureza psicanalítica). (PÊCHEUX \& FUCHS, [1990] 2010, p. 160)

Em Semântica e discurso: uma crítica à afirmação do óbvio, o dispositivo teóricometodológico é deslocado da maquinaria fechada para as relações (desiguais) de forças e de sentidos que se produzem (PÊCHEUX, [1975] 2009). Aí entram as noções de formação discursiva e de interdiscurso e a teoria toma corpo, numa relação de nunca acabar!

\section{Distanciamentos, aproximações, inovações}

Embora Pêcheux tenha se distanciado, em seus textos após a AAD-69, das questões que as máquinas e a informática traziam, esta foi, reafirmo, uma paixão que o perseguiu até o fim.

Segundo Maldidier (2003, p. 72-73), o encontro de Pêcheux com o linguista JeanMarie Marandin abria para o futuro:

Jean-Marie Marandin oferecia uma possibilidade de relance teórico para a análise de discurso. Além disso, ele partilhava com Michel Pêcheux a paixão da informática. Desde 1978 ele reuniu a equipe "Língua, discurso, ideologia" onde ele ia desempenhar um papel essencial na elaboração dos algoritmos de "segunda geração": a AAD80.

Vê-se que a paixão pelas máquinas e pela informática ardia com novo vigor. E era uma tentativa que operava no interior mesmo na Análise de Discurso. Para onde ela ia?

No ano de 1980, o Colóquio intitulado "Materialidades Discursivas" ["Matérialités Discursives"] vai sensivelmente tocar em pontos importantes da Análise de Discurso, com a colaboração de outros pesquisadores (Jean-Marie Marandin, Jacqueline Authier, Jean-Claude Milner, Jean-Jacques Courtine). Aqui, tantos caminhos vão surgindo. Um deles, o da leitura de arquivo, se torna essencial, ao recobrar um problema presente na teoria do discurso desde a AAD-69. A "máquina de ler" fica para trás, dando lugar ao campo do "confronto com os textos sócio-históricos mais diversos", como lemos em Maldidier (2003, p. 80). Mas os algoritmos igualmente se faziam presentes. A questão da informática insistia.

A propósito, Maldidier (idem) também declara que o grupo da Recherche Coopérative Programée (RCP) trabalhou com intensidade sobre o tema da informática em Análise de Discurso. Marandin possibilitou o encontro de Michel Pêcheux e do grupo que o acompanhava com Pierre Plante, da Universidade de Montreal, que havia construído o software DEREDEC. Segundo Ferreira: 
DEREDEC [...] era um software que permitia estocar uma série de informações de diferentes níveis linguísticos (de fonológicos a discursivos), possibilitando também o trabalho com esses diferentes funcionamentos de linguagem. [...] Aqui o projeto era de construir "máquinas paradoxais", que davam espaço a novas hipóteses e abriam o caminho para se prever as falhas do sistema. Pêcheux, como bom estrategista, recuava, quando se sentia vulnerável, mas nunca desistia e tentava avançar com um novo recomeço para uma $\mathrm{AD}$ reconfigurada e, quem sabe, revigorada. (FERREIRA, SEAD/2015)

Tal vínculo interuniversitário fez com que Pêcheux se voltasse à AAD-69 em 1982, quando publicou o texto "Apresentação da análise automática do discurso" juntamente com Jacqueline Leon, Simone Bonnafous e Marandin. Nesse momento finalmente se colocava (por escrito) a problemática que havia envolvido a formulação teórica pecheutiana de 1969, bem como se (re)apresentavam os algoritmos da AAD-69 ao lado das atualizações e dos novos algoritmos que desde então se haviam desenhado. Como exemplo, abandonava-se a ideia de um trabalho em Análise de Discurso constituído por corpora experimentais, tal qual na AAD-69; nesse momento, o da AAD80 , apenas os corpora de arquivo constituíam uma possibilidade efetiva de trabalho. Para além disso, nesse momento, Pêcheux estava interessado na desconstrução das maquinarias discursivas fechadas, isto é, da rigidez do dispositivo que havia sido inicialmente pensada. Através do DEREDEC, isso se tornou mais palpável, à medida que se buscava construir, então, máquinas paradoxais que:

permettent, par un mouvement incessant la production de nouveaux moments de corpus, la formulation de nouvelles hypothèses, l'ouverture de nouveaux trajets à la découverte des réseaux qui constituent l'énoncé. Par un étrange cheminement, Michel Pêcheux retrouve à la fin le Foucault qu'il n'avait pu rencontrer. (MALDIDIER, 1993, on-line) ${ }^{7}$

Ora, a partir do que lemos em Maldidier e em Pêcheux et al., o que se apresentava era um método da análise automática de discurso com novo alento, preocupado com as críticas à AAD-69 e com as perspectivas que surgiam com a AAD-80. Neste momento último, ficava estabelecido que "A confecção de algoritmos de análise do discurso é apenas uma parte de uma problemática mais vasta." (PÊCHEUX et al., [1982] 2010, p. 277), porque i) somente "regiões bem conhecidas" (id., ibid.) seriam suscetíveis de cálculo, contando com hipóteses gerais passíveis de testes em corpora suficientemente vastos, e porque ii) as questões do analista e as interpretações não seriam calculáveis.

Uma série discursiva só poderia então ser descrita considerando "dois espaços [um vertical e outro horizontal $]^{8} \mathrm{e}$, em cada espaço, vários algoritmos que respondem a diferentes definições de objeto" (PÊCHEUX et al., [1982] 2010, p. 277). Isso importa à medida que, conforme colocam os autores, era a significação do sintagma análise do

\footnotetext{
7 "permitem, por intermédio de um movimento incessante de produção de novos momentos de corpus, a formulação de novas hipóteses, abrindo novos caminhos para explorar as redes que constituem o enunciado. Por uma estranha via, Michel Pêcheux finalmente se depara com o Foucault que não havia podido antes encontrar". (tradução livre minha)

8 Trata-se dos dois eixos que Courtine explora em sua tese, conforme Maldidier (2003, p. 86, itálicos da autora): "o eixo vertical da dimensão histórica do discurso e o eixo horizontal do sequenciamento".
} 
discurso que queriam modificar, abandonando uma prática que reduzia uma série discursiva a uma lei ou a um modelo, e promovendo uma prática contraditória que considerasse a morfologia e a leitura.

Tudo isso demonstra que havia uma tecnicidade do trabalho da Recherche Coopérative Programée atuando no seio da Análise de Discurso, refletindo sobre questões de arquivo, de leitura e de memória. Conforme Maldidier (2003, p. 86), "A informática, longe de ser um instrumento neutro, fazia parte integrante da própria pesquisa".

Não à toa, Marandin e Pêcheux escrevem juntos um artigo intitulado "Informática e análise de discurso". ${ }^{9} \mathrm{O}$ texto abre com uma declaração importante:

A referência à informática em Análise do discurso não é nem recente nem o resultado de um efeito de moda. Podem-se citar os programas AAD-69 (M. Pêcheux) e 3AD75 (Del Vigna), entre outros. O principal bloqueio provinha da ausência de analisador sintático suficientemente potente (suscetível de tratar corpora não restritos que não se inscrevessem numa língua técnica) e também de uma colaboração insuficiente com os pesquisadores em informática criadores de programas de análise de textos em língua natural (LN). (MARANDIN \& PÊCHEUX, [1984] 2011, p. 111)

Segundo os autores, duas ordens de escolhas determinavam a referência à informática: uma de política científica e outra metodológica.

Sobre a primeira, Marandin e Pêcheux (idem) falam sobre o momento de desenvolvimentos tecnológicos e sobre o movimento de "resistência cultural à uniformização lógico-semântica" (p. 112), evidenciando que a Análise de Discurso se distancia da Inteligência Artificial e de abordagens quantitativas de representação semântica. A proposta dos autores nesse artigo é demonstrar

que o nível sintático dos fenômenos linguísticos é irredutível a toda abordagem que os assimilaria a um cálculo das intenções de locutores ou a processos mentais que se inscrevam na psicologia dos comportamentos, condutas ou operações. (MARANDIN \& PÊCHEUX, [1984] 2011, p. 112)

A diferença da Análise de Discurso estaria em tomar como determinante a referência à linguística, à sintaxe e à lexicologia, não ignorando a dimensão sintática do léxico e não se reduzindo aos esquemas de análise sêmica.

\footnotetext{
${ }^{9}$ Destacamos a distinção entre este texto e outro intitulado, de forma semelhante, "Análise de Discurso e informática", publicado por Michel Pêcheux em 1981, em Actes du Congrès international: "informatique et sciences humaines". Há tradução em português publicada em Análise de Discurso: Michel Pêcheux (ORLANDI, 2011). Neste texto, Pêcheux, dentre outras coisas, faz uma retrospectiva das relações binárias entre enunciados propostas pela AAD-69 e apresenta um "balanço sobre os diferentes aspectos filosóficos, sócio-históricos, linguísticos e informáticos” (PÊCHEUX, [1981] 2011, p. 280). Lemos nesse texto que o autor queria enfim marcar um lugar distanciado dos procedimentos lógico-empíricos no que concerniam à leitura, encaminhando-se para o tratamento dos arquivos textuais.
} 
Quanto à escolha metodológica, os autores reforçam aquilo que se propunha na AAD-80: que as interpretações e leituras não são passíveis de cálculo. Lemos:

Os procedimentos informatizados visam antes a intervir de maneira regulada sobre o gesto espontâneo ou culto de leitura. Propondo ao olhar leitor recortes heterogêneos do texto a ler, atraindo-o sobre linhas de leitura emaranhadas, constrangendo-o a considerar os níveis opacos à ação de um sujeito (sintaxe, léxico, enunciado), uma Análise de discurso pode mudar a natureza do gesto de leitura: não mais um gesto globalizante no qual a interpretação se confunde com o reconhecimento, mas vários gestos nos quais a interpretação se efetua na tensão. (MARANDIN \& PÊCHEUX, [1984] 2011, p. 113-114)

Ora, vê-se aí uma proposta que se distancia da "máquina de ler" para uma tomada de posição que vincula a informática ao gesto de leitura, na tensão da interpretação. $O$ artigo termina fazendo menção à abordagem do DEREDEC:

Os algoritmos atualmente regulados no grupo Informática e AD buscam multiplicar os ângulos de ataque descritivos; eles podem se reagrupar segundo dois eixos: paradigmático e sintagmático. Os algoritmos paradigmáticos, que exploram a dimensão do enunciado (no sentido de Foucault) estão na entrada lexical ou sintática: eles retomam, para avaliá-los, um certo número de problemas ou de hipóteses tradicionais da AD (construção dos objetos de discurso, pesquisa das zonas de instabilidade...). Os algoritmos sintagmáticos exploram a dimensão do intradiscurso (dinamismo lexical, recortes das sequências, efeitos de sequencialidade sobre os objetos discursivos). Esses algoritmos devem fornecer o quadro de um estudo da enunciação entendida como sistema de lugares para sujeitos. (MARANDIN \& PÊCHEUX, [1984] 2011, p. 114-115)

É visível, então, que o campo da Análise de Discurso pecheutiana nunca se distanciou de fato do dispositivo informático que fez o link lá nos primeiros anos da teoria, quando Pêcheux, sob o pseudônimo de Thomas Herbert, pôs à luz seus textos iniciais. As máquinas, o informático, nunca deixaram de acompanhá-lo, ora mais, ora menos próximo. E o desfecho se comprova com a última comunicação feita por Pêcheux, em julho de 1983, sobre o DEREDEC: "Como prova de que a paixão pelas máquinas o acompanhou até o fim, sua última comunicação em vida, em julho de 1983, foi sobre ' $O$ sistema de programação DEREDEC' ( $C f$. 'Le système de programmation DEREDEC' dans Mots 6, 1983)” (FERREIRA, SEAD/2015).

\section{Tecnologia, linguagem, leitura: revoluções}

Eni Orlandi (2012) escreve que as manifestações da Análise de Discurso não são homogêneas, mas múltiplas. Certamente, as formulações e os avanços que a Recherche Coopérative Programée promoveu nos anos 1980 foram decisivos para pensar o lugar teórico da Análise de Discurso incidindo grandemente sobre uma questão que permanece, 
ainda hoje, atual, fazendo movimento (de) dentro desse campo disciplinar. Pêcheux esteve sempre, e sobretudo, preocupado com as novas tecnologias de linguagem, porque ambas (por isso as destaco) lhe interessavam igualmente. E estava também atento às condições de produção moventes.

Com efeito, em seu texto "Ler o arquivo hoje", de 1982, Pêcheux se interroga sobre as relações entre história e psicologia ligado à leitura de arquivo, considerando o aspecto matemático e informático que envolve a constituição dos bancos de dados e a forma como eles tratam dos arquivos, entendidos, segundo o autor, como "campo de documentos pertinentes e disponíveis sobre uma questão" (PÊCHEUX, [1982] 2010b, p. $51)$.

São muitas as questões problematizadas nesse texto. Tentarei, a seguir, mapear algumas delas. A primeira marca uma diferença:

O discursivo informaticamente marcado sob a forma dos "dados textuais" não tem, efetivamente, a mesma relação nos procedimentos lógico-matemáticos que este outro tipo de dados, de natureza quantitativa, utilizados em economia, em demografia, em história, etc. (PÊCHEUX, [1982] 2010b, p. 49-50)

O que lemos a partir daí, e que Pêcheux marca muito propriamente, é uma diferença entre "culturas": uma mais exata, e outra mais humana, que a história das ideias vai marcar sob a égide do "literário" e do "científico". Desta forma, lemos, ainda:

Por tradição, os profissionais da leitura de arquivos são "literatos" (historiadores, filósofos, pessoas de letras) que têm o hábito de contornar a própria questão da leitura regulando-a num ímpeto, porque praticam cada um deles sua própria leitura (singular e solitária) construindo o seu mundo de arquivos. (PÊCHEUX, [1982] 2010b, p. 50)

Uma segunda questão diz respeito a uma vertente de leitura de arquivos que trata de gerar uma memória coletiva por meio de uma divisão social do trabalho - cuja origem da Idade Média se dava por alguns clérigos que podiam, aliás, eram permitidos, ler, escrever, falar em seus nomes e os outros que também faziam sua leitura, mas por meio de um apagamento do sujeito-leitor em nome da instituição à qual pertencia (PÊCHEUX, [1982] 2010b) - vinculada aos aparelhos de poder das sociedades. A esta divisão caberia, através de gestos de leitura, selecionar, classificar, indexar, codificar, etc., de forma objetiva, os textos.

O que disso resulta é que essa objetividade de classificação, a qual apaga o sujeitoleitor e, consequentemente, o político que promove a divisão social do trabalho ${ }^{10}$, associada à necessidade de gerir os documentos textuais, fez com que se desse a alguns

o direito de produzir leituras originais, logo 'interpretações', constituindo, ao mesmo tempo, atos políticos (sustentando ou

${ }^{10}$ Com efeito, é o político que produz o efeito de apagamento da divisão do trabalho social. 
afrontando o poder local)" e "a outros, a tarefa subalterna de preparar e de sustentar, pelos gestos anônimos de tratamento 'literal' dos documentos, as ditas “interpretações...” (PÊCHEUX, [1982] 2010b, p. $52-53)$

O que isso importa em relação às máquinas?

Ora, os arquivos, em nossos dias, estão nas máquinas, e, mais recentemente, $n a$ nuvem. Pêcheux compreendia como essa relação reorganizava e aprofundava a divisão social do trabalho da leitura:

A lógica das classificações autoriza o desvio da atividade matemática pela gestão administrativa, ou seja, pelo funcionamento de "máquinas" cuja memória é constituída exclusivamente de lembranças, listas e quadros: a palavra "IBM" [International Business Machines] está aí para nos lembrar que a informática tem, espontaneamente, parte ligada à burocracia administrativa. (PÊCHEUX, [1982] 2010b, p. 53).

É preciso frisar que Pêcheux não estava, naquele momento, posicionando-se contra as máquinas, mas reclamando o lugar da memória histórica, discursiva. Tratavase de uma questão política, e a política, como vimos acima, era outra das paixões arrebatadoras de Pêcheux. Por isso é que o posicionamento do autor é contra o "policiamento dos enunciados", a "normalização asséptica da leitura e do pensamento" e o "apagamento seletivo da memória histórica" (idem, p. 55, itálicos do autor).

Por outro lado, manifesta-se que o "fato da língua" é subestimado nos projetos de leituras de arquivo. Nesse ponto reside a proposta de Pêcheux: considerar "a materialidade da língua na discursividade do arquivo" (idem, p. 59) nas práticas sobre os arquivos textuais. E ainda:

nem ceder às facilidades verbais da pura denúncia humanista do "computador", nem se contraidentificar ao campo da informática (o que tornaria a reforçar o projeto desta), mas tomar concretamente partido, no nível dos conceitos e dos procedimentos, por este trabalho do pensamento em combate com sua própria memória, que caracteriza a leitura-escritura do arquivo, sob suas diferentes modalidades ideológicas e culturais, contra tudo o que tende hoje a apagar este trabalho. Isso supõe também construir procedimentos algoritmos informatizados, traduzindo, tão fielmente quanto possível, a pluralidade dos gestos de leitura que possam ser marcados e reconhecidos no espaço polêmico das leituras de arquivos. (PÊCHEUX, [1982] 2010b, p. 59; itálicos do autor)

Mesmo antes deste texto, Pêcheux ([1981] 2011) já se mostrava empenhado em opor-se à recusa histórica que, segundo ele, pareciam cada vez mais presentes no domínio da informática. Um reencontro entre o informático e sua importância para os gestos de leitura então se desenhava, de modo que Pêcheux almejava que o dispositivo informático atuasse no sentido do não-apagamento, mas no da memória e no das muitas formas de ler. 


\section{À guisa de conclusão}

As reflexões apresentadas neste artigo, longe de encerrarem um percurso, abrem para se pensar os modos como a informática e as máquinas afetam o campo teórico da Análise de Discurso. Quero dizer que, de dentro mesmo deste campo, há questões a serem consideradas a respeito de funcionamentos desde o início postos.

Nesse sentido, com este texto puderam-se mapear na obra de Pêcheux pontos de contato com as questões de informática e das máquinas e considerar como o autor preocupou-se com elas em diversos momentos de sua teorização sobre a Análise de Discurso.

Pêcheux ocupou-se, vale aqui repetir, de pensar sobre as máquinas, sobre os algoritmos, sobre os programas e os seus funcionamentos. Não teve tempo de se debruçar sobre a internet (tal como a concebemos hoje, em sua forma moderna), sobre os modos como os sujeitos se inscrevem nesse espaço virtual, sobre como as relações intersubjetivas se dão levando em consideração este espaço. Daí a necessidade de os analistas de discursos continuarmos a jogar luz sobre tais questões. Se, como trouxe com Denise Maldidier na epígrafe deste artigo, "é pela construção de um dispositivo informático que começa a aventura do discurso!" ([1993] 2011, sem indicação de página), tal aventura discursiva continua, agora, considerando aspectos de um dispositivo informático que continua a nos colocar questões.

\section{Referências bibliográficas}

FERREIRA, Maria Cristina Leandro. Conferência de abertura do VII Seminário de Estudos em Análise do Discurso - SEAD, 2015.

HENRY, P. (1969). Os fundamentos teóricos da "análise automática do discurso" de Michel Pêcheux. In: GADET, F.; HAK, T. (Orgs.). Por uma análise automática do discurso: uma introdução à obra de Michel Pêcheux. Trad. Bras. $4^{a}$. ed. Campinas, SP: Editora da Unicamp, 2010.

LUNKES, F. Considerações sobre a construção da Enciclopédia audiovisual de conceitos da Análise do Discurso. Em: MARIANI, B. (Org.). Enciclopédia audiovisual virtual de termos, conceitos e pesquisas em análise do discurso e áreas afins: investigação, inovação, divulgação. Rio de Janeiro: Edições Makunaima; FAPERJ; CNPq, 2016.

MALDIDIER, D. A inquietação do discurso: (re)ler Michel Pêcheux hoje. Trad. Bras. Campinas, SP: Pontes, 2003.

L'inquiétude du discours. Un trajet dans l'histoire de l'analyse du discours: le travail de Michel Pêcheux, Semen [on-line], n. 8, 1993. Disponível em http://semen.revues.org/4351. Acesso em 26 nov. 2015. 
MARANDIN, J-M.; PÊCHEUX, M. (1984). Informática e Análise do discurso. In: PIOVEZANI, C.; SARGENTINI, V. Legados de Michel Pêcheux: inéditos em análise do discurso. São Paulo: Contexto, 2011. p. 111-115.

ORLANDI, E.P. Análise de Discurso e contemporaneidade científica. Em: Discurso em Análise: sujeito, sentido e ideologia. Campinas, SP: Pontes, 2012.

PÊCHEUX, M. (1981). Análise de Discurso e Informática. Em: ORLANDI, E.P. (Org.). Análise de Discurso: Michel Pêcheux. 2a . ed. Campinas, SP: Pontes, 2011.

(1969). Análise automática do discurso (AAD-69). Em: GADET, F.; HAK, T. (Orgs.). Por uma análise automática do discurso: uma introdução à obra de Michel Pêcheux. Trad. Bras. $4^{\mathrm{a}}$. ed. Campinas, SP: Editora da Unicamp, 2010.

(1983). A análise de discurso: três épocas. Em: GADET, F.; HAK, T. (Orgs.). Por uma análise automática do discurso: uma introdução à obra de Michel Pêcheux. Trad. Bras. $4^{\text {a }}$. ed. Campinas, SP: Editora da Unicamp, 2010.

; LEON, J.; BONNAFOUS, S.; MARANDIN, J-M. (1982). Apresentação da análise automática do discurso. Em: GADET, F.; HAK, T. (Orgs.). Por uma análise automática do discurso: uma introdução à obra de Michel Pêcheux. Trad. Bras. $4^{\mathrm{a}}$. ed. Campinas, SP: Editora da Unicamp, 2010.

. (1982). Ler o arquivo hoje. Em: ORLANDI, E.P. (Org.). Gestos de leitura: da história no discurso. $3^{\mathrm{a}}$. ed. Campinas, SP: Editora da Unicamp, $2010 \mathrm{~b}$.

. (1975). Semântica e discurso: uma crítica à afirmação do óbvio. Trad. Bras. $4^{\mathrm{a}}$. ed. Campinas, SP: Editora da Unicamp, 2009.

Artigo recebido em: janeiro de 2017.

Aprovado e revisado em: fevereiro de 2017.

Publicado em: abril de 2017.

Para citar este texto:

ZANELLA, Alexandre da Silva. Um gesto de leitura em Pêcheux: sobre máquinas, informática e arquivo. Entremeios [Revista de Estudos do Discurso, on-line], Seção Estudos, Programa de Pós-Graduação em Ciências da Linguagem (PPGCL), Universidade do Vale do Sapucaí (UNIVÁS), Pouso Alegre (MG), vol. 14, p. 135-147, jan. - jun. 2017.

DOI: http://dx.doi.org/10.20337/ISSN2179-3514revistaENTREMEIOSvol14pagina135a147 